\title{
Resistencia a antibióticos: cuando nuestro armamento se torna ineficiente
}

\author{
Carlos Alberto Lobato Tapia
}

\section{Resumen}

Prácticamente todos hemos necesitado de la administración de algún antibiótico para recuperarnos de cierta infección. Estas sustancias han sido vanagloriadas desde el inicio de su descubrimiento, con ellas nuestra esperanza de vida se ha incrementado de manera significativa y difícilmente nos podríamos imaginar el curso de la humanidad sin su presencia. Sin embargo, no todo es miel sobre hojuelas y, en muchos casos, los que en un principio eran nuestros aliados, actualmente están dejando de ser útiles contra muchas especies bacterianas. Esta situación se ha generado por ciertos mecanismos de resistencia en las bacterias, básicamente debido a la mutación de algunos de sus genes y su transferencia entre ellas. Si la tendencia continúa y no hacemos algo, nos quedaremos sin armas para defendernos de los microorganismos que nos afectan, iregresando a las condiciones en las que nos encontrábamos hace casi 70 años!, con una esperanza de vida menor y elevadas probabilidades de padecer epidemias que en estos días aún podemos controlar. En este artículo se presentan una descripción de la situación, los mecanismos que causan la resistencia, así como algunas recomendaciones de la Organización Mundial de la Salud (OMS), todo ello con la finalidad de hacer conciencia sobre el uso de antibióticos con un fundamento claro.

Palabras clave: resistencia a antibióticos, bacterias, genes resistentes.

\section{Antibiotic RESISTANCE: WHEN OUR DEFENSES BECOME INEFFICIENT}

\begin{abstract}
Practically we all have needed the administration of an antibiotic to recover from an infection. These substances have been so praised since the beginning of their discovery; with them our life expectancy has increased significantly and we could hardly imagine the course of humanity without them. However, not everything is hunky-dory and, in many cases, what were originally our allies are currently becoming non-useful against many bacterial species. This situation has been generated by some resistance mechanisms in bacteria, caused by the mutation of some of their genes and its transfer among them. If this trend continues and we do nothing about it, we will run out of weapons to defend ourselves against the microorganisms that affect us, returning to the conditions in which we were almost 70 years ago! with a lower life expectancy and high probabilities of suffering epidemics that in these days we can still control. In this article we provide a description of the situation, the mechanisms that cause resistance, as well as some World Health Organization (WHO) recommendations; all with the purpose to make conscience about the use of antibiotics with a clear fundament.
\end{abstract}

Keywords: antibiotic resistance, bacteria, resistant genes.

DOI: http://doi.org/10.22201/codeic.16076079e.2019.v20n5.a4 


\section{Carlos Alberto Lobato Tapia}

carlos lob@hotmail.com http://orcid.org/0000-0002-2837-5563

Docente e investigador de la Benemérita Universidad Autónoma de Puebla, en el campus Complejo Regional Nororiental. Su línea de investigación se basa principalmente en el estudio de extractos y compuestos bioactivos de productos naturales propios de la región. Imparte clases de Farmacología, Bioquímica e Inmunología en diferentes licenciaturas del área de la salud. Cuenta con la licenciatura en Químico Farmacéutico Biólogo y un doctorado en Ciencias Biomédicas. Además, una estancia postdoctoral en el Centro de Investigaciones Científicas de Yucatán.

\section{Introducción}

Empecemos definiendo qué son los antibióticos. La oms los define como aquellos medicamentos utilizados para prevenir y tratar las infecciones bacterianas (oms, 2018). El descubrimiento de estos compuestos se ha considerado, por mucho tiempo, como uno de los logros médicos más importantes del siglo xx, pues gracias a ellos se han salvado millones de vidas y además permiten la realización de procedimientos médicos, que de otra manera serían complicados o imposibles, como las cirugías y quimioterapias contra el cáncer (OMS, 2018; WHO, 2017).

El primer compuesto catalogado como antibiótico fue el obtenido por Paul Ehrlich en 1910, conocido con el nombre de Salvarsán, un tratamiento para la sífilis, enfermedad causada por una bacteria de tipo espiroqueta (Treponema pallidum). Y aunque demostró buena eficacia, también presentó una elevada toxicidad, seguramente debido a que su composición presenta átomos de arsénico (Lloyd, Morgan, Nicholson, y Ronimus, 2005). Aunado al descubrimiento de Ehrlich y al uso de sulfas en los fármacos, se sintetizó, por científicos de la empresa farmacéutica Bayer, otro antibiótico denominado Prontosil. Sin embargo, posteriormente se demostró que Prontosil era el precursor de una sustancia que en realidad causaba el efecto, la sulfonamida, el cual, ya era bastante utilizada en la industria del tinte varios años atrás, impidiéndose, por lo tanto, patentar su registro. Este hecho trajo consigo su producción y uso en masa, favoreciendo así, desde esos momentos, la generación de resistencia por parte de los microorganismos (Aminov, 2010).

Seguido de estos dos hallazgos, en 1929 Alexander Fleming reporta en sus cultivos de estafilococos (grupo de bacterias de las cuales varias son patógenas) el crecimiento de un moho, hongo del género Penicillium (similar al que nos encontramos en alimentos como el pan o tortillas después de varios días) y alrededor de éste se mostraba un espacio sin crecimiento de bacterias, espacio conocido como "halo de inhibición" (ver figura 1). Manifestándose, entonces, que 
Figura 1. Fotografía del cultivo de bacterias de Fleming, contaminado con un moho del género Penicillium.

dicho moho posee alguna sustancia que impide el crecimiento de las bacterias. Además, Fleming observó que no sólo inhibía el crecimiento de bacterias del género estafilococo, sino de muchas otras bacterias de importancia clínica (Fleming, 1929).

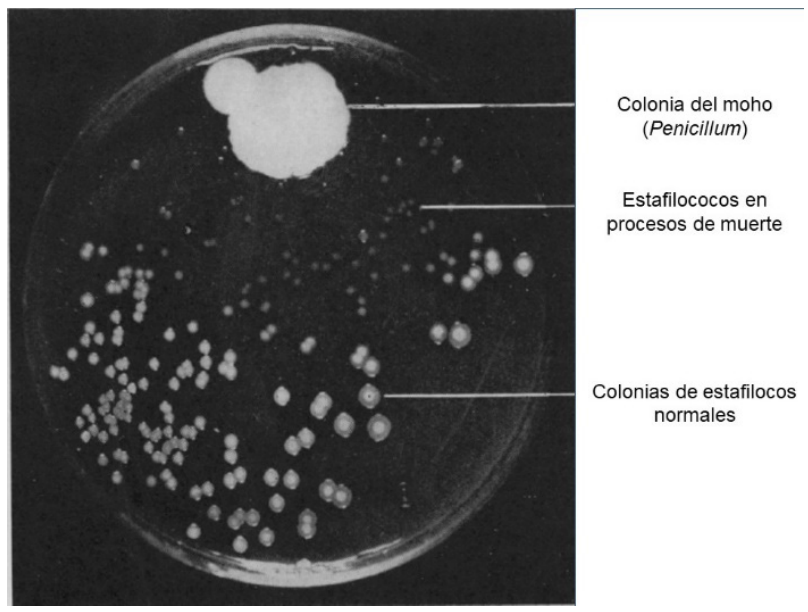

Casi 10 años después, dos científicos de la Universidad de Oxford, Howard Florey y Ernest Chain, consiguen aislar del moho el compuesto responsable de la destrucción bacteriana en los cultivos de Fleming, la penicilina (Kardos y Demain, 2013). Iniciando así, la era de los antibióticos, desarrollándose nuevas y mejores sustancias en las siguientes dos décadas, como la estreptomicina (contra la tuberculosis y bacterias gran negativas sensibles), cloranfenicol (tratamiento para infecciones externas del ojo), tetraciclina (usado para actinomicosis, infecciones del tracto genitourinario, faringitis, neumonía, otitis media aguda y sinusitis, entre otras), vancomicina (contra cocos y bacilos grampositivos así como contra enterococos), quinolona (se emplean en infecciones del tracto urinario, enfermedades de transmisión sexual, osteomielitis crónica, infecciones del tracto respiratorio e infecciones sistémicas graves), entre otras (Katzung, 2015; Saga y Yamaguchi, 2009).

\section{Mecanismos de resistencia a antibióticos}

Pero cuál es el problema si se ha demostrado que estos compuestos son eficaces y su objetivo es aliviar o prevenir enfermedades infecciosas. La situación va de la mano con la evolución, y las bacterias (como todos los organismos) también evolucionan, en este caso, para sobrevivir del daño que les causan los antibióticos, originándose lo que conocemos como resistencia a los antibióticos. Dicha resistencia la podemos definir como la reducción en la efectividad de un fármaco para curar o mejorar los síntomas de una enfermedad (Peet, 2010).

Cabe aclarar que, al hablar de resistencia a antibióticos, nos referimos a que las bacterias son las resistentes a antibióticos y no nosotros, es decir, las resistentes al antibiótico son ellas. Las causas de volverse menos susceptibles a los antibióticos radican, como se mencionó, en su naturaleza evolutiva y con 
ello, la de adaptarse. Sin embargo, contrario a lo que pudiera entenderse, dicha adaptación es meramente azarosa, y no implica que las bacterias sean conscientes de ello o que lo propicien. Simplemente, son mutaciones genéticas aleatorias que les han permitido sobrevivir, como ocurre con todos los seres vivos. En especies como la nuestra, los cambios se aprecian muy poco, ya que de una generación a otra hay muchos años y las observamos sólo por los restos fósiles que se van encontrando. En cambio, en las bacterias, al tener una tasa de reproducción bastante elevada (una bacteria de Escherichia coli se divide cada 30 minutos aproximadamente, originando varios billones de bacterias en menos de 24 horas), sus modificaciones son visibles en un corto período de tiempo. Estas modificaciones, originadas por mutaciones aleatorias, pueden ser favorables o perjudiciales y solamente persistirán aquellas especies que tienen las mutaciones favorables (Alberts et al., 2002). Así, aquellas bacterias que no presentan la mutación benéfica (resistencia a antibióticos) morirán, pero aquellas que sí cuentan con esa mutación sobrevivirán y su descendencia continuará con esa característica.

Dichas mutaciones genéticas han originado procesos que permiten evadir la acción de los antibióticos en las bacterias, como los siguientes (ver figura 2):

- Elaboración de enzimas capaces de degradar los antibióticos.

- Modificar estructuras celulares, de tal forma que los antibióticos no puedan ingresar en ellas y realizar su función.

- Producción de bombas de salida, que devuelven el antibiótico hacia el exterior de la célula.

- Alterar la forma del sitio donde el antibiótico tendría que unirse, impidiendo así su unión y efecto (Oromí, 2014; Tafur y Villegas, 2008).

Figura 2. Mecanismos de resistencia a antibióticos. A) Elaboración de enzimas. B) Modificación estructural. C) Bombas de salida. D) Alteración del sitio de unión del antibiótico.
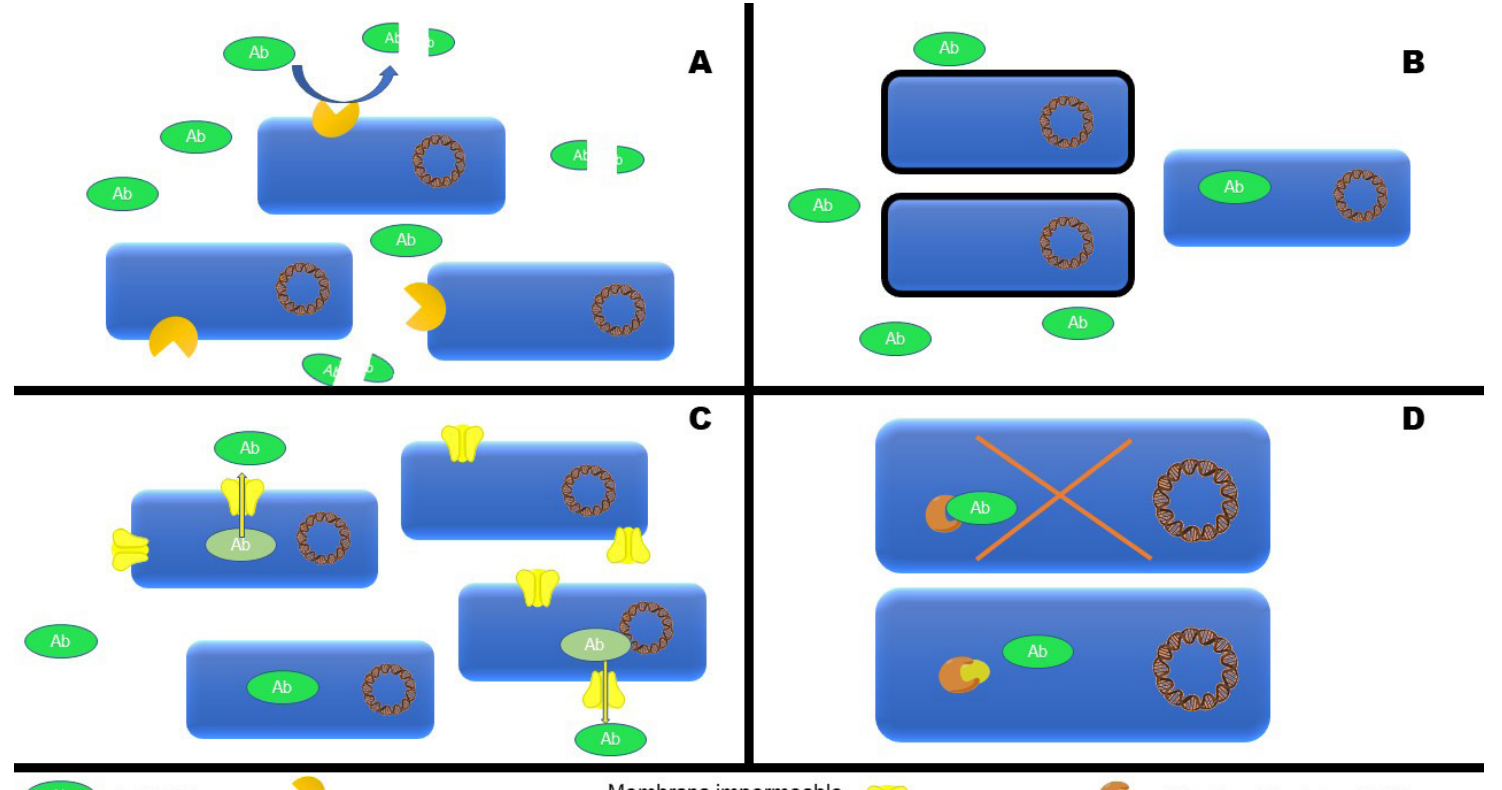

C
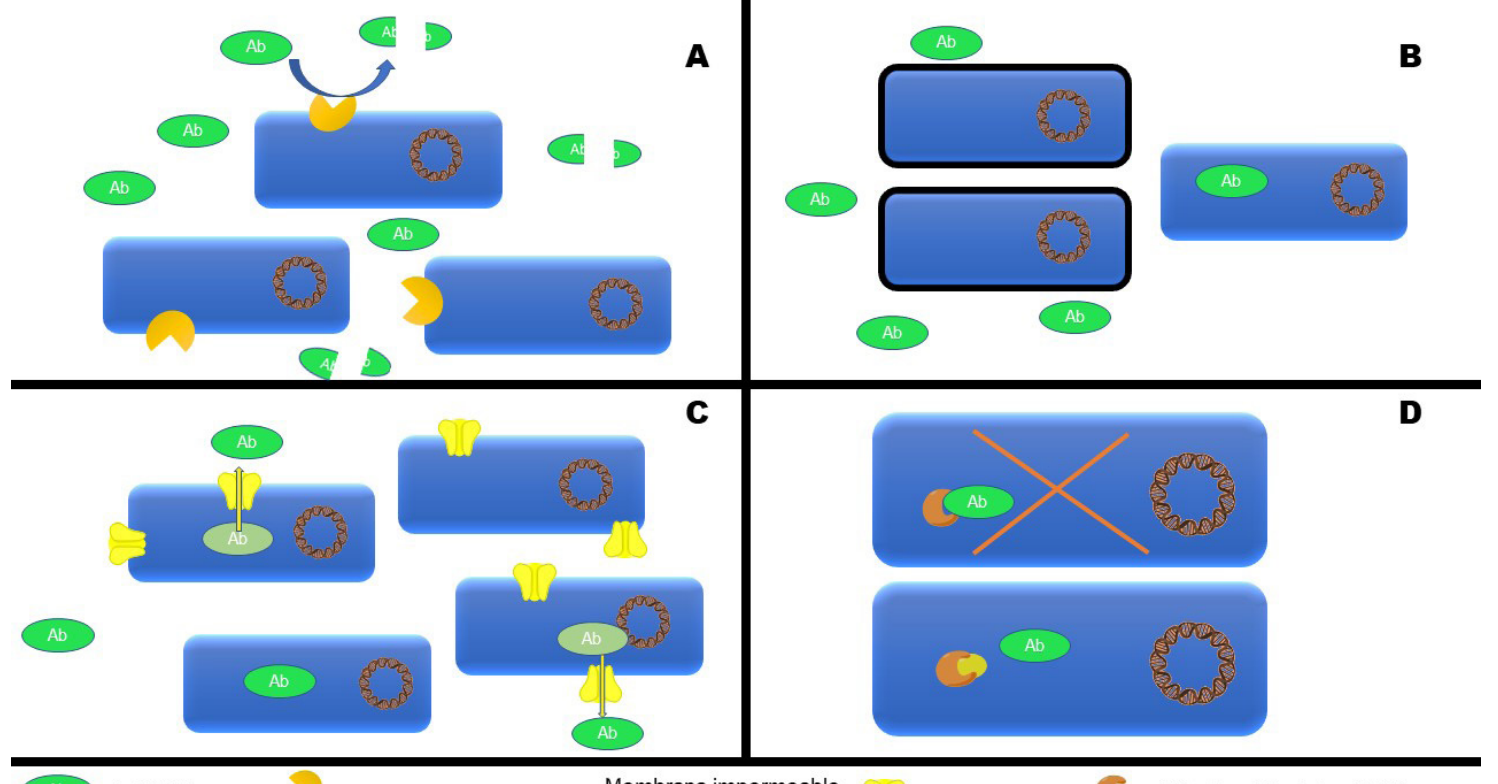

B

Antibiótico

Enzima 
Estos genes "resistentes" son seleccionados en unas cuantas bacterias expuestas a los antibióticos y se ubican en compartimentos pequeños y alejados del resto del material genético, Ilamados plásmidos - pequeñas moléculas de Ácido Desoxirribonucleico (ADN) circular, independientes del cromosoma bacteriano-, por lo que esos fragmentos génicos son más fáciles de difundirse de una bacteria a otra. Esta situación favorece el intercambio de los genes entre diferentes bacterias, permitiendo que bacterias que no eran resistentes, ahora lo sean. Hay diferentes formas en que las bacterias transfieren esa información (ver figura 3), algunos de los procesos de transferencia que se conocen hasta el momento son:

Transducción. Mecanismo llevado a cabo por bacteriófagos (virus que infectan bacterias), los cuales además de insertar su material genético, también pueden llevar algunos genes de otras bacterias.

Conjugación bacteriana. La transferencia de los genes ocurre por contacto directo de bacteria a bacteria y el material genético pasa a través de una especie de puente que conecta a ambas.

Transformación. Este proceso comprende la captación de ADN libre en el medio extracelular hacia la bacteria, seguida de la integración en su material genético y su posterior expresión (utilización).

Agentes de trasferencia génica. Son partículas parecidas a los bacteriófagos que transportan fragmentos génicos de la célula que los libera o produce, éstos salen de la célula y se internalizan en otra (Sánchez, Muñoz y Gutiérrez, 2012; von Wintersdorff et al., 2016).

Figura 3. Mecanismos de transferencia de genes resistentes. A) Transducción. B) Conjugación bacteriana. C) Transformación. D) Agentes de trasferencia génica.
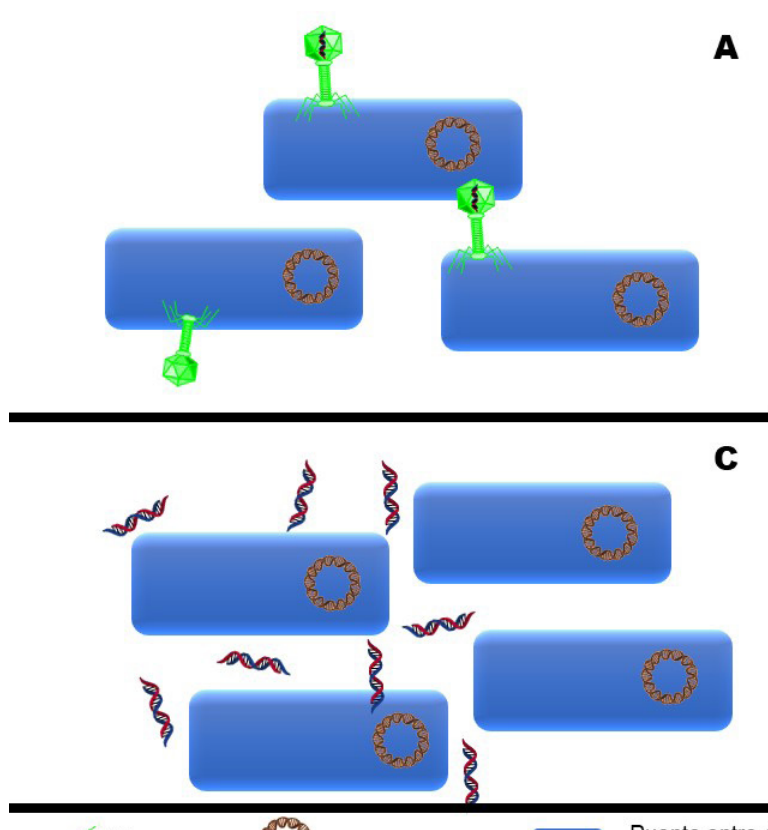

C Virus

A
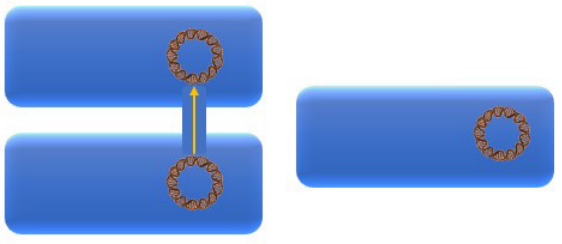

Puente entre dos bacterias

B

D
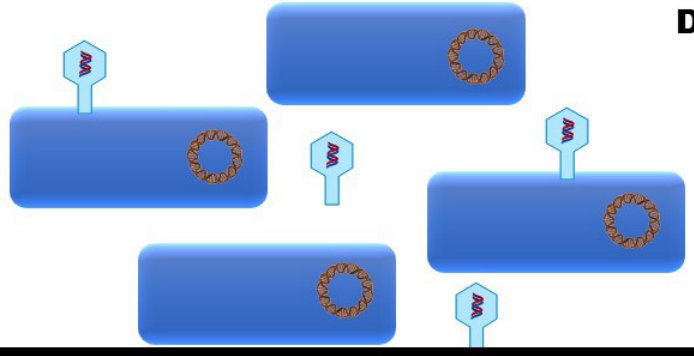

Agentes de transferencia génica 


\section{Uso indiscriminado de antibióticos}

Está de sobra mencionar que los antibióticos nos han ayudado como especie a extender nuestras expectativas de vida, permitiendo recuperarnos de enfermedades infecciosas que, sin ellos, acabarían con nuestras vidas fácilmente. Sin embargo, eso nos ha llevado a su uso exagerado e indiscriminado. Esta razón parece ser la causa de que ahora dichas sustancias comiencen a ser inefectivas ante pequeñas variaciones de los mismos microorganismos, que antes caían inmediatamente ante su poder. Lo más sorprendente es que, desde 1949, Fleming ya advertía del peligro que pudiera traer el uso exagerado de antibióticos (Fleming, 1945).

Así, los antibióticos se usan sin ninguna restricción, se recetan prácticamente por todo tipo de personas, pasando desde los padres que deciden administrarlos a sus hijos sin una valoración médica, cuando nos automedicamos y acudimos a la farmacia, con los vecinos o amigos en busca de algún antibiótico para mejorar algún malestar corporal, e incluso prescritos por médicos para tratar un catarro, cuando su origen es viral (Gérvas, 2000).

Por otro lado, los antibióticos no se emplean únicamente para atender enfermedades en seres humanos, también se utilizan para tratarlas en animales. Por ejemplo, si tu mascota tiene alguna infección de origen bacteriano, lo más probable es que el veterinario le administre antibióticos. Sin embargo, su uso no se enfoca únicamente al tratamiento de mascotas, sino que va más allá, empleándose para tratar enfermedades infecciosas que aquejan a aquellos animales destinados a consumirse como alimento (ganado vacuno, porcino, bovino, peces, etcétera).

Asimismo, se utilizan para prevenir la propagación de enfermedades e incluso para promover un crecimiento más rápido en los animales, aplicando bajas concentraciones de antibióticos, y aunque este último uso se empieza a prohibir en varios países, sigue practicándose en muchos otros (Food and Agriculture Organization [FAO], 2017; Ventola, 2015). El problema ocurre cuando los antibióticos son excretados y llegan a diferentes sitios, propagándose por el medio ambiente, generando así una mayor exposición con los microorganismos e incrementando la probabilidad de originar resistencia a antibióticos.

\section{La participación de la microbiota en la resistencia a antibióticos}

La facilidad de compartir información es crucial en la propagación de la resistencia a antibióticos, causando que cada vez más se encuentren variedades bacterianas resistentes (cepas) que antes no lo eran (Sánchez et al., 2012). ¿Y cómo afecta esa situación en conjunto con el uso indiscriminado de los antibióticos? Ocurre que al no completar un tratamiento favorecemos que 
algunas bacterias sobrevivientes, con mutaciones que las hacen resistentes a antibióticos, las transfieran a bacterias vecinas, mediante los procesos que se describieron anteriormente.

Además, otro aspecto importante, y que tal vez ni nos imaginamos que ocurre, es la existencia de miles de millones de microorganismos (incluyendo bacterias) que viven dentro de nosotros y que influyen en nuestro desarrollo, fisiología, inmunidad y nutrición, formando parte de lo que conocemos como microbiota. De manera general, estos microorganismos (como los lactobacilos) habitan en sitios con tejido mucoso de nuestro cuerpo y una de sus funciones es impedir el crecimiento de microorganismos patógenos, bloqueando posibles infecciones (Vergara et al.2014).

Los antibióticos no distinguen a las bacterias patógenas de las bacterias buenas, por lo que éstas también son susceptibles al ataque de dichas sustancias y, por ende, también de desarrollar mutaciones que favorecen la aparición de genes resistentes a los antibióticos. Así, se ha demostrado que nuestra microbiota, una vez expuesta a los antibióticos, es una fuente importante de genes resistentes y un reservorio potencial para que bacterias patógenas se vuelvan más resistentes (Baron, Diene y Rolain, 2018). Lo que ocurre tanto en una infección, como cuando se toman antibióticos y no es necesario, es la aparición de bacterias resistentes, propias de nuestra microbiota, con la capacidad latente de transferir esa resistencia a bacterias patógenas.

\section{Más allá de la resistencia a antibióticos}

Como un aspecto adicional y, por si fuera poco, las bacterias no sólo generan resistencia a antibióticos, sino que ésta también se ha desarrollado contra los antisépticos y desinfectantes, productos ampliamente comercializados y utilizados tanto en el hogar como en hospitales, centros de salud y laboratorios para evitar la propagación de patógenos. Pero, nuevamente, su uso exagerado y en situaciones innecesarias ha favorecido la aparición de variantes bacterianas resistentes también a ellos (Cabrera, Gómez y Zúñiga, 2007).

Por otro lado, existe un desinterés de la industria farmacéutica en desarrollar nuevos antibióticos, pues al poco tiempo surgen variedades bacterianas resistentes para el nuevo fármaco y, en algunos casos, se sigue prefiriendo el uso de antibióticos previos, por su eficacia y economía. Todo ello genera pocas ganancias para la industria, por lo que la inversión ya no es redituable. Finalmente, la obtención de nuevos antibióticos y su aprobación ante los órganos regulatorios correspondientes se ha tornado más difícil para las compañías, lo que las desalienta. De esta manera, como se menciona anteriormente, la industria ha desatendido el desarrollo de este nuevo tipo de productos (Ventola, 2015), dejándonos así sin nuevas armas contra las bacterias resistentes y con alta capacidad infectiva. 


\section{Recomendaciones a nivel mundial}

Debido a todo lo anterior, es clara la preocupación de los organismos de salud, por lo que la oms declaró que la resistencia a antibióticos es hoy una de las mayores amenazas para la salud mundial, la seguridad alimentaria y el desarrollo, pudiendo afectar a cualquier persona independientemente de su edad o el país en el que viva. Así, se incrementa cada vez más el número de infecciones difíciles de tratar debido a la ineficacia de los antibióticos (OMS, 2018).

Ante esta situación crítica, la oms ha propuesto algunas estrategias claves para prevenir y controlar la propagación de resistencia a antibióticos tales como usar y prescribir antibióticos sólo cuando sean necesarios, no utilizar aquellos que hayan sobrado, cuidar los aspectos básicos de higiene como el lavado de manos y la preparación higiénica de los alimentos, favorecer la prevención de enfermedades infecciosas antes de usar antibióticos, reportar la resistencia de alguna bacteria, así como generar y atender las campañas sobre el buen uso de los antibióticos. La parte agrícola también debe favorecer la higiene para prevenir enfermedades y el uso correcto de antibióticos, al no administrarlos como preventivos ni para el crecimiento del ganado (OMS, 2018).

Por otro lado, el plan de acción de la FAO se basa en desarrollar una capacidad para la vigilancia y el seguimiento de la resistencia a antibióticos en la alimentación y agricultura, promover buenas prácticas en los sistemas alimentarios y agrícolas, basándose en el uso prudente de los antibióticos y, finalmente, concientizar a la población y productores acerca de la resistencia a antibióticos, así como de las amenazas relacionadas (FAO, 2017).

\section{Conclusión}

Es claro que estamos ante un problema grave de salud pública. Si bien a la fecha no parece afectarnos tanto o al menos no se percibe a simple vista, si continúa y no tomamos cartas en el asunto, tanto como profesionales de salud y consumidores, puede llegar a escalas alarmantes, a tal grado de llegar a un momento donde infecciones "leves", que hoy podemos controlar con antibióticos, puedan llegar a ocasionar daños severos e incluso la muerte, ya que no tendríamos con que atacarlos.

Así, con acciones concientizadas — evitar su uso inapropiado, seguir nuestro tratamiento, no tirarlos a la basura corriente y evitar lo más posible su empleo en animales - podemos favorecer que continúe la efectividad de los antibióticos con los que contamos, impidiendo la propagación de bacterias resistentes. Por otro lado, las universidades y centros de investigación deben propiciar el desarrollo de nuevos y mejores antibióticos, e incluso generar alternativas más eficientes a éstos. 


\section{Ligas de interés}

- ¿Sabía que puede haber "superbacterias" en los alimentos?

- Resistencia a los antibióticos. Datos y cifras

- oMs. Antibióticos: Manéjalos con cuidado

- Los Antibióticos No Son Siempre La Solución

\section{Referencias}

Alberts, B., Johnson, A., Lewis, J., Raff, M. y Walter, P. (2002). Molecular Biology of the Cell (4th ed.). Nueva York, NY: Garland Science.

* Aminov, R. I. (2010). A brief history of the antibiotic era: Lessons learned and challenges for the future. Frontiers in Microbiology 1, 134. DOI: HTTPS://DOI. ORG/10.3389/FMICB.2010.00134.

- Baron, S. A., Diene, S. M. y Rolain, J. M. (2018). Human microbiomes and antibiotic resistance. Human Microbiome Journal, 10, diciembre 2018, 43-52 DOI: HTTPS://DOI. ORG/10.1016/J.HUMIC.2018.08.005.

* Cabrera, C. E., Gómez, R. F. y Zúñiga, A. E. (2007). La resistencia de bacterias a antibióticos, antisépticos y desinfectantes una manifestación de los mecanismos de supervivencia y adaptación. Colombia Médica, 38(2), abril-junio. Recuperado de: http://www.scielo.org.co/pdf/cm/v38n2/v38n2a07.pdf.

* Fleming, Alexander (1929). On the antibacterial action of cultures of a Penicillium, with special reference to their use in the isolation of $B$. influenzae. Reviews of Infectious Diseases, 2(1), 129-139. DOI: HTTPS://DOI.ORG/10.1093/CLINIDS/2.1.129.

* Fleming, Alexander (1945). Penicillin [Nobel Lecture]. Recuperado de: https:// www.nobelprize.org/uploads/2018/06/fleming-lecture.pdf.

* Food and Agriculture Organization (FAO). (2017). Antimicrobial resistance in food and agriculture. Recuperdado de: http://www.fao.org/3/a-i7138e.pdf.

* Gérvas, J. (2000). La resistencia a los antibióticos, un problema de salud pública. Atención Primaria, 25(8), 589-596.

* Kardos, N. y Demain, A. L. (2013). Ernst Chain: A great man of science. Applied Microbiology and Biotechnology, 97(15), 6613-6622. DOI: HTTPS://DOI.ORG/10.1007/ s00253-013-5017-4.

- Katzung, B. G. (2015). Basic and Clinical Pharmacology (14a ed.). Nueva York, NY: McGraw-Hill Education/Medical.

- Lloyd, N. C., Morgan, H. W., Nicholson, B. K.y Ronimus, R. S. (2005). The composition of Ehrlich's Salvarsan: Resolution of a century-old debate. Angew. Chem. Int., 44, 941-944. DOI: HTTPS://DOI.ORG/10.1002/ANIE.200461471. 
* Organización Mundial de la Salud (OMS) (2018). Resistencia a los antibióticos. Recuperado de: https://www.who.int/es/news-room/fact-sheets/detail/ resistencia-a-los-antibi\%C3\%B3ticos.

* Oromí, J. (2014). Resistencia bacteriana a los antibióticos [editorial]. Medicina Integral, 36(10). Recuperado de: https://www.elsevier.es/es-revista-medicinaintegral-63-articulo-resistencia-bacteriana-los-antibioticos-10022180.

- Peet, N. P. (2010). Drug resistance: a growing problem. Drug Discovery Today, 15 (15-16), 583-586. DOI: HTTPS://DOI.ORG/10.1016/J.DRUDIS.2010.04.002.

* Saga, T. y Yamaguchi, K. (2009). History of antimicrobial agents and resistant bacteria. Japan Medical Association Journal, 52(2), 103-108. Recuperado de: http:// www.med.or.jp/english/pdf/2009 02/103 108.pdf.

* Sánchez, P., Muñoz, R. y Gutiérrez, N. (2012). Resistencia bacteriana a los antibióticos: mecanismos de transferencia. Spei Domus, 8(17), 31-37. Recuperado de: https://revistas.ucc.edu.co/index.php/sp/article/view/94.

* Tafur, D. y Villegas, V. (2008). Mecanismos de resistencia a los antibióticos en bacterias Gram negativas. Asociación Colombiana de Infectología, 12(3), 217-226. Recuperado de: http://www.sld.cu/galerias/pdf/sitios/apua-cuba/mecanismos de resistencia a los antibioticos en bacterias gram negativas.pdf.

* Ventola, C. L. (2015). The antibiotic resistance crisis: part 1: causes and threats. P \& T: a peer-reviewed journal for formulary management, 40(4), 277-283. Recuperado de: https://www.ncbi.nlm.nih.gov/pmc/articles/PMC4378521/.

* Vergara, D. M., Ferrer, I. C., Ortega Annló, E. y González Sánchez, M. E. (2014). Probióticos: más allá de la salud intestinal. Nutr Hosp., 30(Supl. 2), 63-67.

von Wintersdorff, C. J. H., Penders, J., van Niekerk, J. M., Mills, N. D., Majumder, S., van Alphen, L. B., ... Wolffs, P. F. G. (2016). Dissemination of Antimicrobial Resistance in Microbial Ecosystems through Horizontal Gene Transfer. Frontiers in Microbiology, 7, 173. Dol: https://doi.org/10.3389/fmicb.2016.00173.

* World Health Organization. (2017). Antibacterial agents in clinical development: an analysis of the antibacterial clinical development pipeline. Recuperado de: https:// www.who.int/medicines/areas/rational use/antibacterial agents clinical development/en/.

\section{Cómo citar este artículo}

* Lobato Tapia, Carlos Alberto (2019). Resistencia a antibióticos: cuando nuestro armamento se torna ineficiente. Revista Digital Universitaria (RDU). Vol. 20, núm. 5 septiembre-octubre. Dol: http://doi.org/10.22201/codeic.16076079e.2019.v20n5. a4.

Recepción: 11/03/19. Aprobación: 28/06/19. 